\title{
Stones in the retrocaval ureter
}

\author{
Abeygunasekera Anuruddha M, Wijayagunawardane Saranga, Samaraweera WMCK, \\ Dissanayake Gayaman \\ Colombo South Teaching Hospital, Kalubowila, Sri Lanka
}

Correspondence to: Dr.Anuruddha MAbeygunasekera(amabey@sltnet.lk)

\section{Introduction}

Retrocaval ureter is one of the rarest congenital anomalies. Here the ureter deviates medially and passes behind the inferior vena cava winding about and crossing in front of it from medial to lateral side. However this is due to a developmental anomaly of the embryonic veins forming the IVC rather than an anomaly of the ureteric development. Most patients present with loin pain. Occasionally calculi may form above the obstruction.

\section{Case report}

A 53-year old man developed right abdominal pain. Abdominal ultrasonography showed right hydronephrosis and hydroureter with several stones inside the dilated upper ureter. There were gall stones too. An IVU did not delineate the upper urinary tract clearly due to poor renal function (Figure 1). The CT IVU showed a retrocaval ureter with several stones lodged inside the dilated upper ureter (Figure 2).

Surgical intervention is indicated in the presence of functionally significant obstruction leading to pain or other complications like stone formation or urosepsis. Right ureter was approached by a right subcostal incision below the twelfth rib. The proximal and distal ureteric segments were isolated (Figure 3). The ureter medial to and posterior to the IVC was gently separated. After division of the ureter the stones were removed and the spatulated distal segment was anastomosed to the proximal dilated segment using 3-0 polyglactin sutures across a $6 \mathrm{Fr}$ double J ureteric stent anterior and lateral to the IVC. Patient had an uneventful recovery and the ureteric stent was removed after 6 weeks.

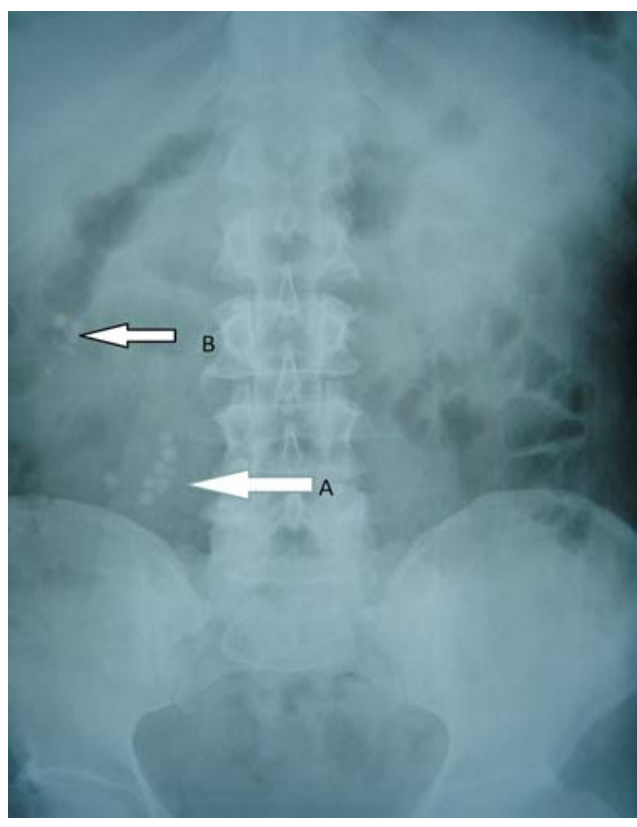

Figure 1: Control film of the IVU showing stones in the curved upper ureter (arrow A) and gall stones (arrow B)

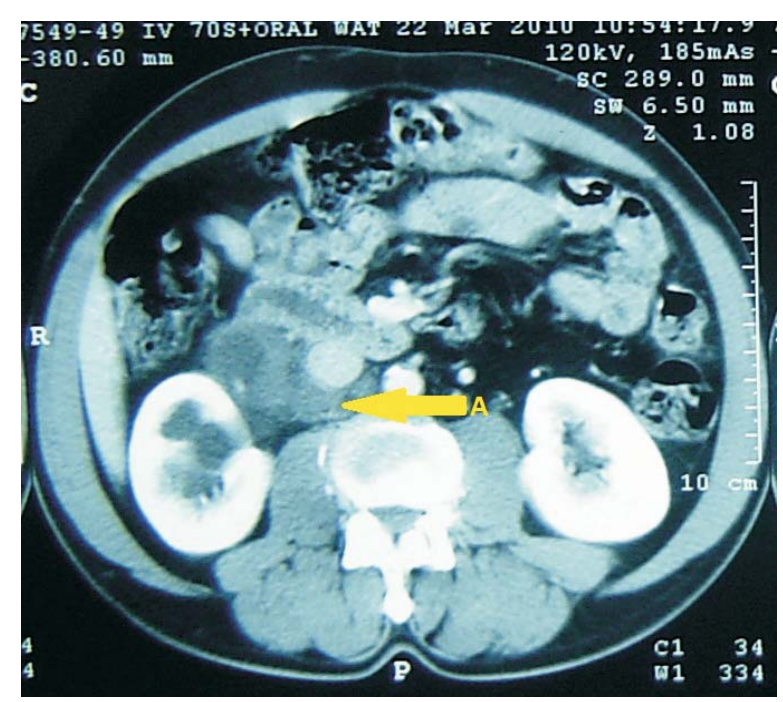

Figure 2: CT IVU showing upper ureter passing posterior to the IVC (arrow A) 


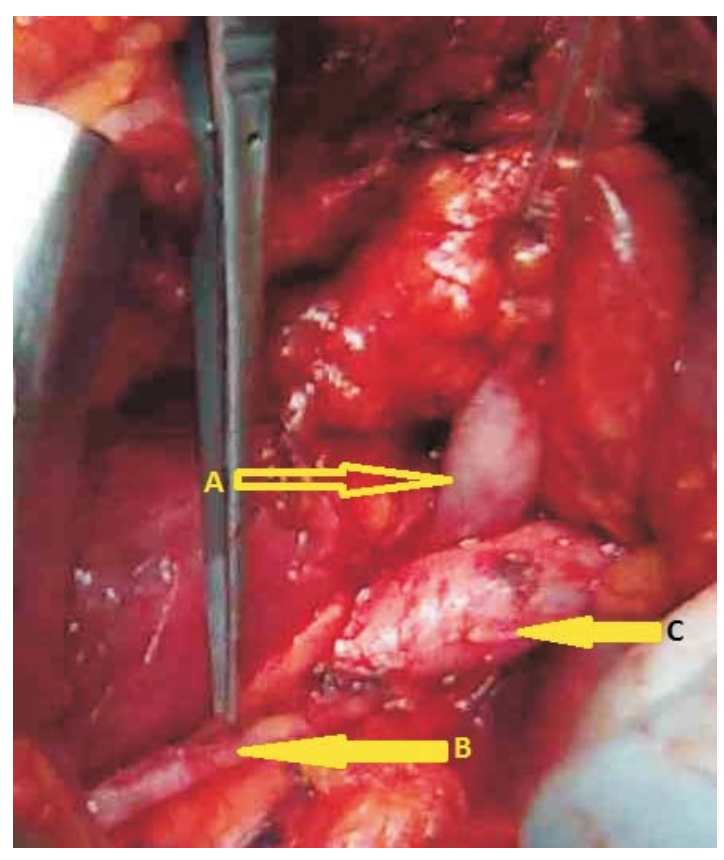

Figure 3: Intraoperative photograph showing proximal (arrow A) and distal (arrow B) ureteric segments and IVC (arrow C)

\section{Discussion}

Though retrocaval ureter is a congenital abnormality it does not develop symptoms until the third or fourth decade of life.

The IVC normally develops from the posterior cardinal, subcardinal, and supracardinal veins which undergo sequential development, anastomosis and regression to become the IVC and azygous system (1). Normally the right subcardinal veins form the prerenal IVC, the subcardinal-supracardinal anastomosis forms the renal segment and the right supracardinal vein forms the post renal IVC. Left supracardinal vein and lumbar portion of right posterior cardinal vein atrophy. If the subcardinal vein in the lumbar portion fails to atrophy and becomes primary right side vein the ureter is trapped dorsal to it.
Retrocaval ureter is classified into two types based on its radiographic appearance and the site of crossing the IVC (2). In type I as in our case, the ureter crosses the IVC at the level of the third lumbar vertebra and has a fish hook shaped (S shape) appearance. In the type II, the ureter crosses the IVC at a higher level near the renal pelvis. The curve is smooth and sickle shaped and degree of hydronephrosis is less severe or non-existent. Almost all symptomatic cases of retrocaval ureter appear to be type I anomalies (3). Treatment of the retrocaval ureter entails anteriorisation of the ureter and ureteroureterostomy. If there are stones, those should be removed.

\section{References}

1. Cavazzola LT, Groisman R, de Oliveria VF. Transcaval ureter: case report and a review of the literature European Journal of Anatomy, 2005; 9: 59-62.

2. Kenawi MM, Williams DI. Circumcaval ureter. A case report of four cases in children with a review of literature and a new classification British Journal of Urology, 1976; 48: 183.

3. Sathesan B, Prabath API, Goonewardena SAS. Retrocaval ureter: a venous anomaly causing ureteric obstruction Sri Lanka Journal of Urology, 2009; 10: 18-21. 